\title{
THE RELATIONSHIP BETWEEN ANTIBIOTIC THERAPY IN EARLY CHILDHOOD AND THE SYMPTOMS OF ALLERGY IN CHILDREN AGED 6-8 YEARS - THE QUESTIONNAIRE STUDY RESULTS
}

FILIP RACIBORSKI ${ }^{1,2}$, ANETA TOMASZEWSKA ${ }^{1}$, JAROSŁAW KOMOROWSKI ${ }^{1}$, PIOTR SAMEL-KOWALIK ${ }^{1}$, ARTUR Z. BIALOSZEWSKI ${ }^{1}$, ARTUR WALKIEWICZ ${ }^{1}$, ADAM LUSAWA', JAKUB SZYMAŃSKI ${ }^{1}$, DAGMARA OPOCZYŃSKA ${ }^{1}$, MICHAŁ DRUŻBA ${ }^{1}$, JACEK BOROWICZ', AGNIESZKA LIPIEC ${ }^{1}$, WOJCIECH J. KAPALCZYNSKI ${ }^{3}$, and BOLESŁAW SAMOLIŃSKI ${ }^{1}$

${ }^{1}$ Medical University of Warsaw, Warszawa, Poland

Department of Prevention of Environmental Hazards and Allergology

${ }^{2}$ Institute of Rheumatology, Warszawa, Poland

Department of Epidemiology and Health Promotion

${ }^{3}$ University of Texas Health Science Center at San Antonio, San Antonio, TX, United States

Department of Internal Medicine

\begin{abstract}
Introduction: Studies based on the ISAAC questionnaire suggest a correlation between the use of antibiotics and the prevalence of asthma and allergy in children aged 6-7 years. The number of courses of antibiotic therapy is an important factor. Objectives: To investigate the relationship between the use of antibiotics during the first years of life and the prevalence of allergy and asthma among children (aged 6-8 years) in the urban population of Poland. Materials and Methods: A survey-based study with a self-completed questionnaire. The respondents were parents of children aged 6-8 years living in Warszawa, Poland. 1461 completed questionnaires were collected. Results: Asthma was declared in $4.3 \%$ of the children. Wheezing and/or sibilant rhonchi within 12 months before the study was observed in $13.5 \%$ of the cases. Asthma medication was taken by $21.8 \%$ of the children. Allergic rhinitis was declared in $18.7 \%$ of the children. Problems with sneezing, rhinorrhea, and nasal congestion not associated with cold or fever were observed in $40.7 \%$ of the children. The analysis of the odds ratios between the use of antibiotics and the symptoms of allergic diseases revealed a clear correlation. The highest odds ratio was observed between the completion of over three courses of antibiotic therapy prior to the age of 12 months and the declaration of one of the following: asthma ( $\mathrm{OR}=5.59,95 \% \mathrm{CI}$ : 2.6-12.01), wheezing and/or sibilant rhonchi $(\mathrm{OR}=4.68,95 \% \mathrm{CI}: 3.01-7.27)$ and taking medicines for breathlessness (OR = 5.12, 95\% CI: 3.42-7.68). Conclusions: There is a direct relationship between antibiotic use in the first 3 years of life and asthma and allergy symptoms in children aged 6-8 years old.
\end{abstract}

Key words:

Asthma, Allergy, Antibiotics, Epidemiology, Prevalence, Risk factors

Received: April 25, 2012. Accepted: September 3, 2012.

Address reprint request to F. Raciborski, Department of Prevention of Environmental Hazards and Allergology, Medical University of Warsaw, Banacha 1A, 02-097 Warszawa, Poland (e-mail: filip.raciborski@wum.edu.pl). 


\section{INTRODUCTION}

Several scientific publications on asthma and allergy epidemiology in industrialized countries show an increase of asthma and rhinitis prevalence [1-4]. The study Epidemiology of Allergic Disease in Poland (ECAP) showed the occurrence of allergic rhinitis in $23.6 \%$ of $6-7$-yearolds [5]. Furthermore, the overall prevalence of asthma among children and teenagers aged 3 to 16 was $8.6 \%$ [6] in the Polish Multicentre Study of Epidemiology of Allergic Diseases (PMSEAD).

The prevalence of allergic diseases among children is higher in the urban areas than in the rural ones. Asthma and allergic rhinitis were recognized in $16.42 \%$ and $38.81 \%$ of urban children 12-16years of age and in $1.97 \%$ and $10.84 \%$ of rural children 12-16 years of age, respectively [7]. The observed differences in the prevalence of allergic diseases between the rural and urban populations are consistent with the "hygiene hypothesis". The hygiene hypothesis explains the correlation of the rise in the prevalence of allergic diseases to decreased family size and infection, and increased immunizations [8,9].

Studies conducted throughout the world have demonstrated a connection between asthma prevalence and specific pharmacotherapies, especially paracetamol, in the intra-uterine environment [10-13] and in early childhood $[14,15]$. Also, a direct relationship has been observed between paracetamol use and the development of rhinitis in children aged 6-7 years [16].

Another ISAAC study involving 258000 children from fifty-six countries showed a statistically significant inverse relationship between antibiotic sales per capita and asthma-related symptoms prevalence $(\mathrm{p}=0.021)$. The opposite relationship was observed with rhinitis, but it was not statistically significant $(\mathrm{p}=0.076)$ [17].

An analysis of the Swedish Prescribed Drug Register conducted in children born between July 2005 and June 2009 (211 000 records) shows a strong relationship between antibiotic usage and the prescription of asthma medication [18]. However, Almqvist demonstrated that this is not true for all antibiotics. Antibiotics used to treat Gram-positive infections, such as those common in the respiratory tract, did reveal a statistically significant relationship. Antibiotics used to treat Gram-negative infections, such as those of the urinary tract, skin and soft tissue, showed no such statistically significant association.

In Poland, the most popular antibiotics are the semisynthetic penicillin derivatives, particularly Amoxicillin. Cephalosporins (e.g. cefaclor, cefadroxyl, and cefuroxym) are also commonly used. Other antibiotics are less frequently prescribed to children below the age of 36 months. The number of medical indications for the use of macrolids among children increases after 24 months of life. The most commonly prescribed macrolids are claritromicin and azithromycin.

Taiwanese studies (involving 2037 children) based on the ISAAC questionnaire phase III, have shown the association between the use of antibiotics in children during the infancy and the prevalence of asthma in early childhood (OR $=2.35,95 \%$ CI: $1.52-3.66)$ [19].

Additionally, research publications have demonstrated a possible link between the frequency of antibiotic course completion in early childhood and the risk of asthma development later in life [20-22].

The goal of this study was to assess the relationship between the use of antibiotics in early childhood and the prevalence of allergies, asthma, and their associated symptoms in the urban early-primary-school age group in Poland.

\section{MATERIALS AND METHODS}

The questionnaire study was conducted in December 2009 and January 2010 in primary schools across Warszawa, Poland. Forty-two out of 172 registered primary schools in Warszawa were selected as the sample group. In each of the schools, all first-grade children were included in the 
study. The systematic sampling was representative for the target group (school-aged children from the first grade in Warszawa).

The parents or legal guardians of those children were the respondents in the study and they completed the questionnaires. The questionnaires were distributed by the teachers to the children to be given to their parents/ guardians. 1525 out of 3164 questionnaires provided to the schoolteachers were returned making a response rate of $49 \%$. Subsequently, 1461 fully completed questionnaires were verified and accepted for further analysis. $85.8 \%$ of the children in the test group were born in 2002, $11.6 \%$ in 2003 and $2.7 \%$ in 2001.

Each questionnaire consisted of 64 questions in three sections: information about the guardian and the household, early childhood and environmental factors, and health status (allergic disease symptoms). The questions related to asthma and allergy symptoms were chosen from the International Study of Asthma and Allergies in Childhood (ISAAC) and the European Community Respiratory Health Survey II (ECRHS II version). ISAAC and ECRHS II questions were adapted and validated to match the Polish conditions for ECAP (Epidemiology of Allergic Disease in Poland, www.ecap.pl) study purposes.

The questionnaire contained two questions regarding antibiotic therapy: "How many times was your child treated with antibiotics before he/she was 12 months old?" (question 42) and "How many times was your child treated with antibiotics when he/she was 13-36 months old?" (question 43).

The symptoms of asthma and allergy were measured on the basis of the answers to the following questions: 47) Has your child taken any medicines for breathlessness or problems with breathing?; 48) Has your child had wheezing or whistling sounds in the chest at any time in the last 12 months?; 49) Has your child ever been diagnosed with asthma?; 51) Has your child ever had a problem with sneezing or a runny or congested nose when she/he did not have a cold, fever or flu?; 53) Does your child have any nasal allergies, including a runny nose caused by allergy to pollens (hay fever)?; 59) Has your child ever had any transient itchy rashes for at least 6 months?; 61) Has your child ever had an allergic reaction after an insect bite in the past?; 62) Is your child allergic to any foods?

IBM SPSS Statistics 20 software was used for statistical analysis. The differences in the prevalence of allergy symptoms between the groups (including sex groups) were tested by chi-squared test. Part of the analysis was done separately for the groups of boys and girls. The relationships between the variables were measured using odds ratios (OR). Moreover, multivariate binary logistic regression analyses were carried out. Eight models were built, one for each symptom of allergic diseases separately. The dependent variable was the symptom of allergic disease. The independent variables were as follows: the use of antibiotics in the first year of life, the use of antibiotics when the child was aged between 13 and 36 months (both variables were inputted as qualitative variables) and of the sex of the child. For all the tests, a p-value of $<0.05$ was considered significant.

\section{RESULTS}

\section{Antibiotic therapy administration}

1446 (99\%) out of 1461 respondents answered the question about administering antibiotics during the first year of their children's life. $35.3 \%$ of the parents claimed that they had not administered any antibiotics to their children, $27.5 \%$ had administered antibiotics only once, $17.2 \%$ had administered antibiotics two or three times and $12 \%$ said they had given antibiotics to their children more than 3 times. $8 \%$ of the respondents did not answer the question.

$32.4 \%$ of the boys and $37.7 \%$ of the girls did not take any antibiotics by the age of one year. Antibiotics were more 
often given to boys $(\mathrm{p}=0.006)$. Certain differences were also observed in the antibiotic use frequency. $14.5 \%$ of the boys and $9.9 \%$ of the girls were treated with antibiotics more than 3 times.

$1456(99.7 \%)$ out of 1461 respondents answered the question about administering antibiotics to children aged between 13 and 36 months. $12.1 \%$ of the parents claimed that during that time they had not administered any antibiotics, $32.1 \%$ had used them 1-2 times and $23.6 \%$ had used them 3-4 times. $10.9 \%$ said they had given antibiotic 5-6 times and $12.2 \%$ more than 6 times. $9.3 \%$ of the respondents could not answer the question.

The parents' answers to these questions showed a statistically significant association with the sex of the child $(p=0.021)$. Between the ages of $13-36$ months, $10 \%$ of the boys and $13.9 \%$ of the girls received no antibiotics, while $25.5 \%$ of the boys and $20.9 \%$ of the girls were given antibiotics more than five times in the same period.

\section{Asthma and allergy symptoms}

The incidence of asthma and allergy symptoms in the study group was more often declared among the boys. Recognized asthma was declared by the parents of $6.0 \%$ of the boys and $2.8 \%$ of the girls $(p=0.004)$. Wheezing or sibilant rhonchi in the last twelve months was observed in $15.0 \%$ of the boys and $12.8 \%$ of the girls (the difference not statistically significant, $p=0.143$ ). Drugs for treating breathlessness or difficulty with breathing were taken by $26.1 \%$ of the boys and $18.1 \%$ of the girls $(p<0.001)$.

The parents of the boys declared allergy or its symptoms more often. Allergic rhinitis affected $20.8 \%$ of the boys and $16.8 \%$ of the girls (the difference not statistically significant, $p=0.054)$. Sneezing, rhinorrhea, and nasal congestion not associated with cold or fever were observed in $44.2 \%$ of the boys and $37.7 \%$ of the girls ( $p=0.017$ ). Itchy rash for at least 6 months was observed in $33.8 \%$ of the boys and $32.4 \%$ of the girls (the difference not statistically significant, $p=0.652$ ). Allergic reactions to insect bites were confirmed in $21.0 \%$ of the boys and $26.9 \%$ of the girls $(p=0.020)$. Parents claimed that $21.1 \%$ of the boys and $20.9 \%$ of the girls were allergic to food (the difference not statistically significant, $\mathrm{p}=0.896$ ).

Table 1 presents asthma and allergy occurrence, relating to the history of antibiotic therapy.

\section{Coexistence of asthma and allergy symptoms and antibiotic therapy during the first year of life}

Table 1 shows a clear correlation between the prevalence of asthma and allergic disease symptoms and antibiotic use in the first 12 months of life. Declarations of asthma and allergic nasal symptoms in the groups stratified on the basis of antibiotic use in the first year of life are presented in Figure 1. There is a direct relationship between the use of antibiotics and asthma in the age group of 6-8-year-olds. The prevalence of asthma in children, who did not receive antibiotics in their first year of life, is $2.2 \%$. Asthma was present in $11.0 \%$ of the respondents in the group in which antibiotics were used over 3 times.

The prevalence of allergic nasal symptoms varied statistically significantly according to the number of antibiotic courses in the first year of life only in the group of girls $(p<0.001)$. Among the boys, the differences in the distribution of this factor turned out not to be statistically significant $(p=0.268)$.

The correlations between the use of antibiotics in the first year of life and the symptoms of allergic diseases

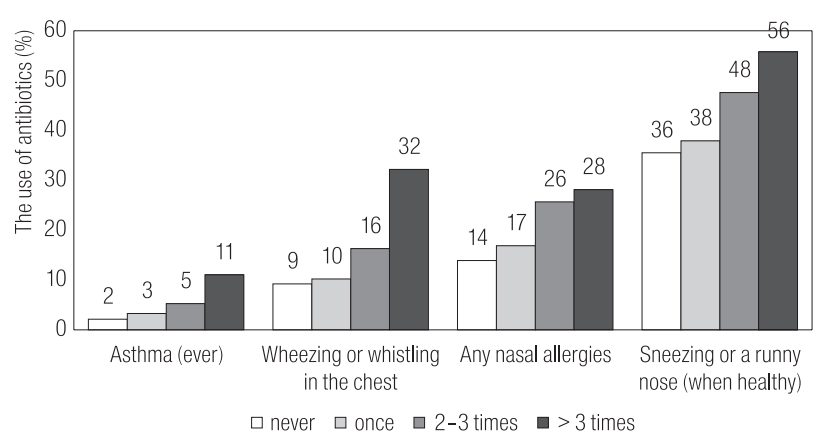

Fig. 1. The use of antibiotics during the first 12 months of a child's life and asthma and allergy symptoms $(\mathrm{N}=1330)$ 


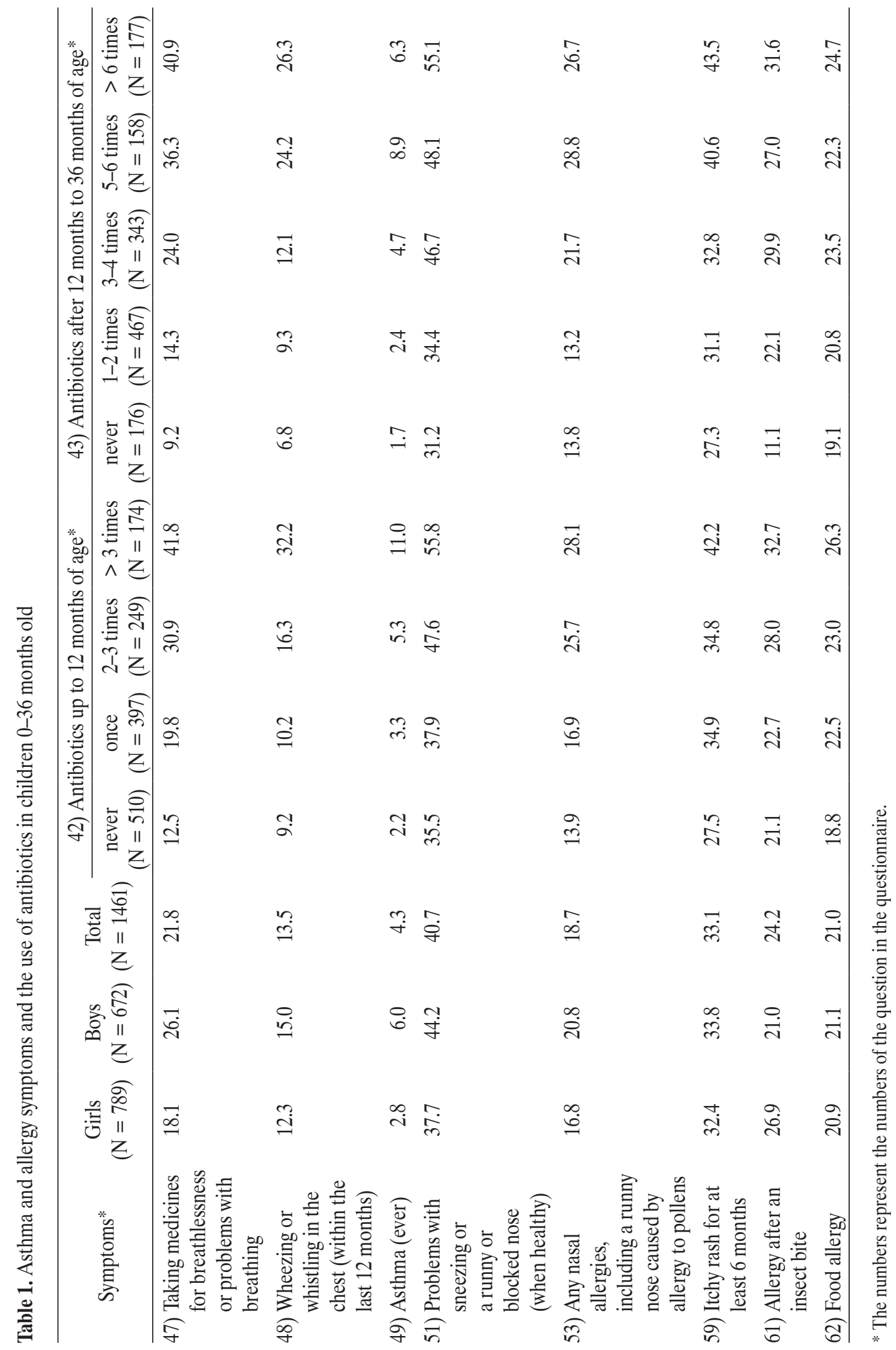


Table 2. Relationship (odds ratio) between the use of antibiotics during the first 12 months of life and the symptoms of allergic diseases in the early childhood*

\begin{tabular}{|c|c|c|c|c|c|c|}
\hline \multirow{3}{*}{ Symptoms** } & \multicolumn{6}{|c|}{ The use of antibiotics } \\
\hline & \multicolumn{2}{|c|}{$\begin{array}{c}\text { once } \\
(\mathrm{N}=397)\end{array}$} & \multicolumn{2}{|c|}{$\begin{array}{l}2-3 \text { times } \\
(\mathrm{N}=249)\end{array}$} & \multicolumn{2}{|c|}{$\begin{array}{l}>3 \text { times } \\
(\mathrm{N}=174)\end{array}$} \\
\hline & OR & $\mathrm{p}$ & OR & $\mathrm{p}$ & OR & $\mathrm{p}$ \\
\hline $\begin{array}{l}\text { 47) Taking medicines for breathlessness } \\
\text { or problems with breathing }\end{array}$ & 1.73 & 0.003 & 3.17 & $<0.001$ & 5.12 & $<0.001$ \\
\hline $\begin{array}{l}\text { 48) Wheezing or whistling in the chest } \\
\text { (within the last } 12 \text { months) }\end{array}$ & 1.12 & 0.612 & 1.93 & 0.004 & 4.68 & $<0.001$ \\
\hline 49) Asthma (ever) & 1.54 & 0.296 & 2.55 & 0.020 & 5.59 & $<0.001$ \\
\hline $\begin{array}{l}\text { 51) Problems with sneezing or a runny } \\
\text { or blocked nose (when healthy) }\end{array}$ & 1.13 & 0.392 & 1.66 & 0.001 & 2.42 & $<0.001$ \\
\hline $\begin{array}{l}\text { 53) Any nasal allergies, including a runny nose } \\
\text { caused by allergy to pollens }\end{array}$ & 1.28 & 0.193 & 2.15 & $<0.001$ & 2.48 & $<0.001$ \\
\hline 59) Itchy rash for at least 6 months & 1.43 & 0.014 & 1.43 & 0.032 & 1.95 & $<0.001$ \\
\hline 61) Allergy after an insect bite & 1.09 & 0.602 & 1.44 & 0.042 & 1.83 & 0.002 \\
\hline 62) Food allergy & 1.23 & 0.217 & 1.30 & 0.175 & 1.52 & 0.045 \\
\hline
\end{tabular}

* The point of reference was the group without any antibiotic therapy $(\mathrm{N}=510)$.

** The numbers represent the numbers of the question in the questionnaire.

The analysis excluded the people who were unable to remember whether a child under 12 months of age received antibiotics.

$\mathrm{OR}$ - odds ratio.

are presented in Table 2. The strongest correlations among the analyzed factors were observed when the children had been given antibiotics more than three times, compared to the group that had not received any antibiotics. The highest odds ratios were recorded between the group of children who had received three or more courses of antibiotics and the declaration of asthma (OR $=5.59,95 \% \mathrm{CI}: 2.6-12.01)$, taking medicines for breathlessness $(\mathrm{OR}=5.12,95 \%$ CI: 3.42-7.68), and wheezing or sibilant rhonchi (OR $=4.68$, 95\% CI: 3.01-7.27).

In most analyzed cases, there was no proof of statistical relationship (measured by the odds ratio) between the rare use of antibiotics (only once in the first year of life) and reporting the symptoms of allergic diseases. The exceptions are: taking medicines for breathlessness $(\mathrm{OR}=1.73,95 \% \mathrm{CI}: 1.21-2.49)$ and an itchy rash for at least 6 months (OR $=1.43,95 \%$ CI: $1.08-1.91)$.

\section{Coexistence of asthma and allergy symptoms, and antibiotic therapy between 13-36 months of age}

The incidence asthma and allergic diseases in the examined children also varied depending on the use of antibiotics between the age of 13 and 36 months (Table 1). Figure 2 presents selected information on the link between asthma and allergy and the use of antibiotics during that period.

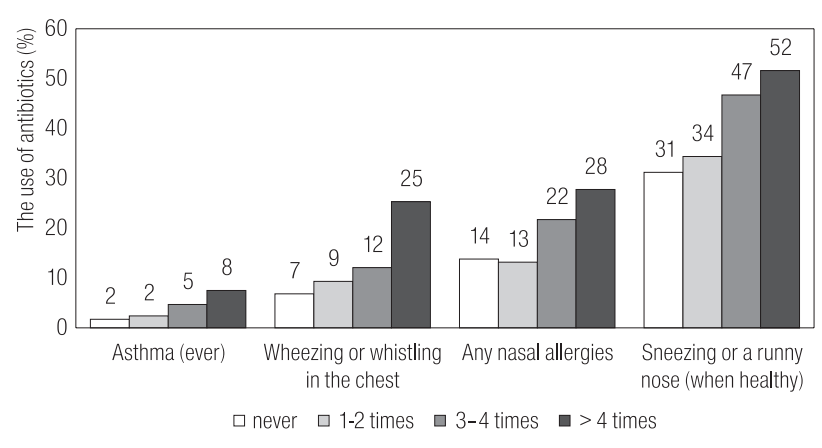

Fig. 2. The use of antibiotics from the age of 13 to 36 months and asthma and allergy symptoms $(\mathrm{N}=1321)$ 
The occurrence of asthma in children who had not received antibiotics between 13 and 36 months of age was $1.7 \%$. Asthma was present in $8.9 \%$ of the children who had been given antibiotics 5-6 times and in $6.3 \%$ of the children who had taken antibiotics more than 6 times. This finding suggests that the use of antibiotics increases the likelihood of asthma at an early school age (Figure 2). Additionally, data analysis revealed that the prevalence of asthma varied depending on the number of antibiotic therapies in the group of girls ( $p=0.014)$, yet there was no such relationship among the boys $(\mathrm{p}=0.161)$.

The prevalence of allergic nasal symptoms varied statistically significantly according to the number of antibiotic courses applied between 13 to 36 months of age among the girls only $(\mathrm{p}<0.001)$. Among the boys, the differences in the distribution of this factor turned out not to be statistically significant $(\mathrm{p}=0.114)$.
Analysis of the odds ratios between the use of antibiotics, when a child was between 13 and 36 months of age, and the symptoms of allergic diseases revealed a correlation (Table 3). The strongest relationship between the analyzed factors was observed when the children had been given antibiotics more than four times in comparison to the group who had not received any antibiotics. The highest odds ratio was observed for the relationship between using antibiotics four or more times and the declaration of: taking medicines for breathlessness $(\mathrm{OR}=5.12,95 \%$ CI: 3.42-7.68), wheezing or sibilant rhonchi $(\mathrm{OR}=4.65,95 \% \mathrm{CI}: 2.46-8.78)$ and asthma (OR $=4.73,95 \%$ CI: 1.41-15.90).

In most analyzed cases, there was no proof of statistical relationship (measured by the odds ratio) between the rare use of antibiotics (only once or twice when a child was between 13 and 36 months of age) and reporting the

Table 3. Relationship (odds ratio) between the use of antibiotics from the age of 13 months to 36 months and the symptoms of allergic diseases in the early childhood*

\begin{tabular}{|c|c|c|c|c|c|c|}
\hline \multirow{3}{*}{ Symptoms** } & \multicolumn{6}{|c|}{ The use of antibiotics } \\
\hline & \multicolumn{2}{|c|}{$\begin{array}{l}1-2 \text { times } \\
(\mathrm{N}=467)\end{array}$} & \multicolumn{2}{|c|}{$\begin{array}{l}3-4 \text { times } \\
(\mathrm{N}=343) \\
\end{array}$} & \multicolumn{2}{|c|}{$\begin{array}{l}>4 \text { times } \\
(\mathrm{N}=335)\end{array}$} \\
\hline & OR & $\mathrm{P}$ & OR & $\mathrm{p}$ & OR & $\mathrm{p}$ \\
\hline $\begin{array}{l}\text { 47) Taking medicines for breathlessness or } \\
\text { problems with breathing }\end{array}$ & 1.65 & 0.086 & 3.12 & $<0.001$ & 6.34 & $<0.001$ \\
\hline $\begin{array}{l}\text { 48) Wheezing or whistling in the chest } \\
\text { (within the last } 12 \text { months) }\end{array}$ & 1.41 & 0.310 & 1.89 & 0.060 & 4.65 & $<0.001$ \\
\hline 49) Asthma (ever) & 1.42 & 0.594 & 2.87 & 0.084 & 4.73 & 0.006 \\
\hline $\begin{array}{l}\text { 51) Problems with sneezing or a runny or } \\
\text { blocked nose (when healthy) }\end{array}$ & 1.15 & 0.453 & 1.94 & 0.001 & 2.41 & $<0.001$ \\
\hline $\begin{array}{l}\text { 53) Any nasal allergies, including a runny nose } \\
\text { caused by allergy to pollens }\end{array}$ & 0.98 & 0.937 & 1.80 & 0.023 & 2.44 & $<0.001$ \\
\hline 59) Itchy rash for at least 6 months & 1.20 & 0.354 & 1.31 & 0.193 & 1.97 & 0.001 \\
\hline 61) Allergy after an insect bite & 2.28 & 0.002 & 3.39 & $<0.001$ & 3.38 & $<0.001$ \\
\hline 62) Food allergy & 1.12 & 0.615 & 1.32 & 0.233 & 1.32 & 0.241 \\
\hline
\end{tabular}

* The point of reference was the group without any antibiotic therapy $(\mathrm{N}=176)$.

** The numbers represent the numbers of the question in the questionnaire.

The analysis excluded the people who could not remember whether a child between 13 and 36 months of age received antibiotics.

$\mathrm{OR}$ - odds ratio. 
symptoms of allergic diseases. The exception is allergy symptoms after exposure to hymenoptera venom after bites by these insects ( $\mathrm{OR}=2.28,95 \% \mathrm{CI}$ : $1.35-3.87)$.

A multivariate binary logistic regression analysis was carried out separately for each symptom of allergic diseases. Eight models were created according to the analyzed question. The explanatory power of the regression models was relatively low. Cox \& Snell R squared ranged from 0.089 (for taking medicines for breathlessness or problems with breathing) to 0.004 (for food allergy), depending on the symptom being explained. In all the developed models, the use of antibiotics on one occasion in the first year of life was statistically insignificant (the reference level was not taking any antibiotics in that period). The use of antibiotics three times or more during the first year of life proved to be statistically associated with the declaration of: taking medicines for breathlessness $(\mathrm{OR}=2.80, \mathrm{p}<0.001)$, wheezing or sibilant rhonchi in the chest $(\mathrm{OR}=2.85$, $\mathrm{p}<0.001)$, asthma (OR $=3.17, \mathrm{p}=0.020)$ and problems with sneezing, runny nose, or congestion $(\mathrm{OR}=1.71, \mathrm{p}=0.016)$.

In all the models, the relationship between the symptoms of allergic diseases and the use of antibiotics once or twice between 13 and 36 months of age was statistically insignificant (the reference level being no antibiotics administered in that period). The use of antibiotics four times or more during the first year of life proved to be statistically associated with the declaration of: taking medicines for breathlessness $(\mathrm{OR}=3.93, \mathrm{p}<0.001)$, wheezing or sibilant rhonchi $(\mathrm{OR}=2.71, \mathrm{p}=0.008)$, problems with sneezing or a runny or congested nose $(\mathrm{OR}=1.86, \mathrm{p}=0.008)$, itchy rash for at least 6 months $(\mathrm{OR}=1.67, \mathrm{p}=0.034)$ and allergy after an insect bite $(\mathrm{OR}=2.95, \mathrm{p}<0.001)$.

The sex of the examined children was a statistically significant factor in all models except nasal allergies and food allergy, as the boys presented a higher likelihood of developing symptoms of allergic diseases.

\section{DISCUSSION}

The connection between antibiotic use in early childhood and asthma [23,24] and allergic diseases is not shown in all published studies [23,25]. For instance, Celedón's analyses did not show a direct relationship between asthma and allergy in early childhood and antibiotic use. In that study, a group of 448 children with a parental history of atopy was followed from birth. When the potential confounders were eliminated, there was no statistically important relationship between antibiotic use in the first year of life and asthma, wheezing, allergic rhinitis or eczema at the age of 5.

The data presented in this article partially supports the hypothesis that a relationship exists between the administration of antibiotics during the first months of life, and the subsequent prevalence of allergies, asthma and their symptoms in childhood. The effect is observed mainly among girls, where the correlations between the use of antibiotics in the first year of life and in the period from 13 to 36 months of age were both linked to atopy. It might be that frequent antimicrobial therapy administration in healthy boys is responsible for weaker statistical relationship in comparison to girls. Due to the nature of the study and the type of statistical analysis applied, other potentially relevant factors were not accounted for. The factors that were not measured in the study may have a significant impact on the presented results. For example, the information about the onset of allergic diseases was not collected in the study. It is important because children with unrecognized asthma in early age may be treated with antibiotics when they have an asthmatic attack. There is a risk that a physician may mistake asthma symptoms with an infection and apply incorrect treatment. In consequence, early antibiotic treatment may be a marker of early onset of asthma. This factor is a potential and important confounder, which should be considered in subsequent studies.

Additionally, an important problem is the reliability of the declarations in such questionnaire-based surveys. Asthma and allergic diseases are often underdiagnosed in 
Poland [26]. The data about asthma and allergic diseases declarations are possibly misleading and may not show the current epidemiological status, although such data is commonly used for the estimation of allergy and asthma incidence [4]. For this reason, in many cases, statements relating to the symptoms rather than the diagnosis of allergic diseases are more reliable.

There are also other methodological limitations. Reporting the symptoms of allergic diseases by the respondents in the survey questionnaire cannot be treated equally to medical examination. However, due to the significant problem with undiagnosed asthma and allergic rhinitis in Poland, asking respondents about the symptoms confirmed by physicians is also not an effective method. The solution would be to concurrently conduct the medical examination and the questionnaire, but this was not possible in this study. Declarations about taking antibiotics are also probably biased. The collected data may show lower percentages of children who received antibiotics at least once. 8-9\% of parents were unable to answer the questions about antibiotic treatments. Also, the response rate at the level of $49 \%$ can hypothetically bias the results. There is no evidence that the problem of nonresponse has systematic character, but this should be considered.

The presented results are not unequivocal. Based on this study, one cannot determine whether antibiotic therapy is the cause of allergies or allergy is the cause of antibiotic therapy. Infections requiring antibiotics are often observed in children with asthma and allergy.

It is also possible that in children with allergies and asthma, due to the clinical similarities of these conditions and infectious disease symptoms, the frequent use of antibiotics is the result of incorrect diagnosis leading to the overuse of antimicrobial drugs.

Regardless of the relationship between asthma, allergies and their symptoms, and the use of antibiotics, the survey still revealed a troubling phenomenon. The results indicate that antibiotics are overused in Poland. There are no epidemiological data to justify such frequent use of this drug in the first period of life. Only $9.5 \%$ of the surveyed parents declared that their child was not treated with antibiotics between birth an 36 months of age. Such frequent antibiotic use is a problem requiring an immediate solution. The data presented in this article is congruent with the hygiene hypothesis of allergy incidence. The information provided by this study could help us establish an allergy and asthma prevention program and could help us lower the cost of the health care system in Poland.

\section{CONCLUSIONS}

There is a direct correlation between antibiotic use in early childhood and, both, asthma and allergy symptoms in children 6-8 years.

\section{REFERENCES}

1. Eder W, Ege MJ, Mutuis Evon. The asthma epidemics. N Engl J Med 2006;355:2226-35.

2. The International Study of Asthma and Allergies in Childhood (ISAAC) Steering Committee. Worldwide variation in prevalence of symptoms of asthma, allergic rhinoconjunctivitis, and atopic eczema. Lancet 1998;351:1225-32.

3. European Community Respiratory Health Survey. Variations in the prevalence of respiratory symptoms, self-reported asthma, and use of asthma medication in the European Community Respiratory Health Survey. Eur Respir J 1996;9:687-95.

4. Asher MI, Montefort S, Bjorksten B, Lai CK, Strachan DP, Weiland SK, et al. Worldwide time trends in the prevalence of symptoms of asthma, allergic rhinoconjunctivitis, and eczema in childhood: ISAAC Phases One and Three repeat multicountry cross-sectional surveys. Lancet 2006;368:733-43.

5. Samoliński B, Sybilski AJ, Raciborski F, Tomaszewska A, Samel-Kowalik P, Walkiewicz, et al. Prevalence of rhinitis in Polish population according to the ECAP (Epidemiology of Allergic Disorders in Poland) study. Otolaryngol Pol 2009;63(4):324-30. 
6. Liebhart J, Malolepszy J, Wojtyniak B, Pisiewicz K, Plusa T, Gladysz U. Prevalence and Risk Factors for Asthma in Poland: Results From the PMSEAD Study. J Investig Allergol Clin Immunol 2007;17(6):367-74.

7. Majkowska-Wojciechowska B, Pełka J, Korzon L, Kozłowska A, Kaczała M, Jarzebska M, et al. Prevalence of allergy, patterns of allergic sensitization and allergy risk factors in rural and urban children. Allergy 2007;62(9):1044-50.

8. Strachan DP. Hay fever, Hygiene, and household size. BMJ 1989;299:1259-60.

9. Strachan DP. Family size, infection and atopy: the first decade of the "hygiene hypothesis". Thorax 2000;55(Suppl 1):S2-10.

10. Shaheen SO, Newson RB, Sherriff A, Henderson AJ, Heron JE, Burney PG, et al. Paracetamol use in pregnancy and wheezing in early childhood. Thorax 2002;57:958-63.

11. Shaheen SO, Newson RB, Henderson AJ, Headley JE, Stratton FD, Jones RW, et al. Prenatal paracetamol exposure and risk of asthma and elevated immunoglobulin $E$ in childhood. ClinExp Allergy 2005;35:18-25.

12. Rebordosa C, Kogevinas M, Sorensen HT, Olsen J. Pre-natal exposure to paracetamol and risk of wheezing and asthma in children: a birth cohort study. Int J Epidemiol 2008;37(3):583-90.

13. Persky V, Piotrkowski J, Hernandez E, Chavez N, WagnerCassanova C, Vergara C, et al. Prenatal exposure to acetaminophen and respiratory symptoms in the first year of life. Ann Allergy Asthma Immunol 2008;101(3):271-8.

14. Cohet C, Cheng S, MacDonald C, Baker M, Foliaki S, Huntington $\mathrm{N}$, et al. Infections, medication use, and the prevalence of symptoms of asthma, rhinitis and eczema in childhood. J Epidemiol Community Health 2004;58:852-7.

15. Wong GW, Leung TF, Ma Y, Liu EK, Yung E, Lai CK. Symptoms of asthma and atopic disorders in preschool children: prevalence and risk factors. Clin Exp Allergy 2007:37(2):174-9.

16. Beasley R, Clayton T, Crane J, von Mutius E, Lai CK, Montefort $\mathrm{S}$, et al. Association between paracetamol use in infancy and childhood, and risk of asthma, rhinoconjuncticitis, and eczema in children aged 6-7 years: analysis from Phase Three of the ISAAC programme. Lancet 2008;372:1039-48.
17. Asher MI, Stewart AW, Mallol J, Montefort S, Lai CK, AitKhaled N, et al. Which population level environmental factors are associated with asthma, rhinoconjunctivitis and eczema? Review of the ecological analyses of ISAAC Phase One. Respir Res 2010;11:8. DOI: 10.1186/1465-9921-11-8.

18. Almqvist C, Wettermark B, Hedlin G, Ye W, Lundholm C. Antibiotics and asthma medication in a large register-based cohort study - confounding, cause and effect. Clin Exp Allergy 2012;42(1):104-11.

19. Yeh KW, Ou LS, Yao TC, Chen LC, Lee WI, Huang JL, et al. Prevalence and risk factors for early presentation of asthma among preschool children in Taiwan. Asian Pac J Allergy Immunol 2011;29:120-6.

20. McKeever TM, Lewis SA, Smith C, Collins J, Heatlie H, Frischer M, et al. Early exposure to infections and antibiotics and the incidence of allergic disease: a birth cohort study with the West Midlands General Practice Research Database. J Allergy Clin Immunol 2002;109:43-50.

21. Marra F, Marra CA, Richardson K, Lynd LD, Kozyrskyj A, Patrick DM, et al. Antibiotic use in children is associated with increased risk of asthma. Pediatrics 2009;123:1003-10.

22. Kozyrskyj AL, Ernst P, Becker AB. Increased risk of childhood asthma from antibiotic use in early life. Chest 2007;131:1753-9.

23. Celedon JC, Litonjua AA, Ryan L,Weiss ST, Gold DR. Lack of association between antibiotic use in the first year of life and asthma, allergic rhinitis, or eczema at age 5 years. Am J Respir Crit Care Med 2002;166:72-5.

24. Celedon JC, Fuhlbrigge A, Rifas-Shiman S, Weiss ST, Finkelstein JA. Antibiotic use in the first year of life and asthma in early childhood. Clin Exp Allergy 2004;34:1011-6.

25. Bremner SA, Carey IM, DeWilde S, Richards N, Maier WC, Hilton SR, et al. Early-life exposure to antibacterials and the subsequent development of hay fever in childhood in the UK: case-control studies using the General Practice Research Database and the Doctors' Independent Network. Clin Exp Allergy 2003;33:1518-25.

26. Komorowski J, Samoliński B, Rabczenko D, Sybilski A. The estimation of conformability between the questionnaire 
diagnosis of asthma and the diagnosis based on clinical examination. ECAP study (Epidemiology of allergic diseases in Poland) [abstract]. XXVIII Congress of the European Academy of Allergy and Clinical Immunology; 2009 Jun 6-10; Warszawa, Poland. Allergy 2009;64(Suppl 90):330.

This work is available in Open Access model and licensed under a Creative Commons Attribution-NonCommercial 3.0 Poland License - http://creativecommons.org/ licenses/by-nc/3.0/pl/deed.en. 